\title{
Research of Interdisciplinary Cooperation in the Management of Cardiovascular Emergencies through the Covid-19 Pandemic; A Review of Literature.
}

\author{
Foteini Kaskani' and Alexandros Mihopoulos ${ }^{2}$
}

\begin{abstract}
The management of emergency cardiovascular events and especially cardiac arrest, which is occurring more and more often globally, requires the establishment of special interdisciplinary teams (blue code, RRT), both to prevent its occurrence and to increase survival rates. Special communication and organization tools of these groups (SBAR, RSVP) have been established worldwide and attention has been given to the development of non-technical skills of their members (ANTS). The aim of this review was to examine the current literature on the function and effectiveness of interdisciplinary teams in the treatment of in-hospital cardiovascular emergencies during the Covid-19 pandemic. Studies from USA, Sweden, Brazil and S. Korea showed a reduction of mortality and numbers of in-hospital cardiac arrests after RRT teams implementation and interventions. Covid-19 pandemic is resulting in delaying in CPR implementation to emergency incidents as these teams are required to use special both personal and general protective equipment while managing these incidents. Despite differentiations among countries and health systems globally, it's comprehensible that interdisciplinary teams have to be reinforced by the set-up and implementation of programs and training courses both to improve survival and save heath recourses.
\end{abstract}

Keywords: Emergency cardiac diseases, Cardiac arrest, Cardiopulmonary resuscitation, Interdisciplinary teams, Pandemic, Coronavirus/covid-19.

${ }^{1}$ RN, Santarosa 6, Preveza, Greece.

${ }^{2} \mathrm{RN}, \mathrm{Msc}, \mathrm{PhD}$, Assistant Professor in Faculty of Nursing, University of Peloponnese, Greece.

Article Info: Received: January 3, 2021. Revised: January, 102021.

Published online: January 11, 2021. 


\section{Introduction}

The term 'Interdisciplinary' defines the cooperation among health scientists from different disciplines to achieve a common goal, through a patient-centered approach.[1] Communication tools of interdisciplinary teams such as 'SBAR' (Situation, Background, Assessment and Recommendation) can help teams focus on communication and enhance the process of exchanging information.[2] SBAR is especially significant in emergencies, when clear and effective interpersonal communication is crucial to patients' progress.[2] A communication enhancement system is 'RSVP' (Reason, Story, Vital Signs, Plan), which includes basic information that allows interdisciplinary teams to response appropriately.[3] Furthermore, non-technical skills (as analyzed in the ANTS program- Anesthetists Non-Technical Skills) can be defined as the mental, social and individual skills that complement the technical skills and contribute to the satisfactory performance of work.[4] They enhance employees' technical skills and include situational awareness, decision-making ability, teamwork, leadership skills, stress and fatigue management, predictability, clear communication and team coordination optimizing the management of health emergencies, especially cardiovascular diseases.[4]

The most common emergencies in cardiovascular diseases are mainly pulmonary embolism, acute pulmonary edema, dangerous arrhythmias, acute myocardial infarction and particularly the especially urgent often referred to as cardiopulmonary arrest (CA), which refers to the cessation of cardiac mechanical activity, i.e. the expulsion of blood from the heart pump.[5] Survival rates of cardiopulmonary arrest are associated with immediate recognition of patients at risk, early diagnosis and effective treatment.[6] Every year 475.000 people in the USA die of cardiac arrest, while in Europe rate ranges from 1 to 5 cases per 1000 admissions, while in general population it is estimated that 400.000 people suffer from sudden cardiac arrest each year with survival rate of 5-8\%.[7,8] In England, an estimated number of 60.000 cardiac arrests occur every year, of which 30.000 are successfully treated.[8]

The term 'Cardiopulmonary Resuscitation' (CPR) refers to the urgent treatment required to overcome circulatory and respiratory failure.[9] It is divided into Basic CPR or Basic Life Support and Advanced Cardiac Life Support that requires special knowledge and is applied in-hospital by interdisciplinary teams using special equipment and medicines.[9] The 'Blue Code' is a key hospital emergency code used to alert a response team, when cardiopulmonary arrest occurs.[10]

According to the ERC 2015 ALS, if an unconscious patient is identified, the resuscitation/blue code team is called. The patient is connected to a monitor/cardiograph or better to a defibrillator (if available) and CPR is applied [30:2 chest compressions/breaths] or defibrillation.[7] Advanced Life Support will be provided when the resuscitation team arrives. If there are signs of life, an assessment is made based on a given algorithm, treatment through $\mathrm{O}_{2}$ supply and I.V. administration.[7] Based on above, each hospital should have an effective 
resuscitation team, staffed by trained staff in Advanced Life Support. Its members are usually from 4 to 6 and mainly concern a training manager in CPR (usually as a 'leader'), a cardiologist, an anesthesiologist/ intensivist and a nurse.[11]

Rapid Response Systems are used by hospitals to identify and treat patients in emergency care by calling interdisciplinary teams.[12] Such teams are 'MET' (Medical Emergency Teams) led by a doctor, 'RRT' (Rapid Response Teams) led by a doctor or nurse and 'CCOT' (Critical Care Outreach Teams) led by a nurse.[13] These teams replace (or coexist with) traditional cardiac arrest teams that typically response to patients, who already have cardiac arrest, and they have the appropriate equipment to start CPR immediately, when needed.[14] Criteria for responding these teams are usually staff concerns about parameters such as blood pressure and heart rate disorders and the decreased level of consciousness.[12] RRT have already been implemented in the USA, Europe, Australia and Canada.[14] The MET and RRT teams are interdisciplinary teams consisting of medical and nursing emergency care staff with the aim of rescuing patients through appropriate and timely treatment.[14]

In these teams the members, usually, form a triangular resuscitation formation, where the leader is outside of triangle and takes care of organization and safety of the group.[15] In position 1 is the initial assessment, the start of compressions and is always in the right side of the patient. In position 2, on the left side of patient, the defibrillator is managed and the patches are placed. Finally, in position 3, on the patient's head, the airway is managed and the gases are monitored. Effective interdisciplinary teamwork and communication are key to patient survival.

It is undisputable that technical skills such as correct defibrillation, effective chest compressions, the recognition of cardiac arrhythmias and rapid drug delivery are especially significant for patient survival.[16] However, the 5 main categories of non-technical skills that are leadership, communication, mutually assessment, protocol maintenance and task management play a crucial role in the effective treatment of cardiac arrest.16] Finally, nurses are integral part of all this service, participating as equal members in the resuscitation team, without being limited only to the recognition and calling for help. $[9,17]$

The effectiveness of interdisciplinary teams in the midst of the current pandemic of Covid-19 is being tested daily, globally, as issues such as speed of action, incident assessment and use of personal protective equipment are evolving as global scientific and epidemiological data evolve.

\section{Aim and Method}

\subsection{Aim}

The aim of this literature review is to investigate reports on the function and effectiveness of interdisciplinary teams in the treatment of in-hospital cardiovascular diseases through the Covid-19 pandemic. 


\subsection{Method}

A report review of the electronic databases 'Pubmed', 'Google Scholar', 'Scopus', 'iatrotek.gr', 'ekt.gr' between Jan. and Nov. 2020 with key-words as: interdisciplinary, emergency cardiac diseases, cardiac arrest, cardiopulmonary resuscitation, pandemic $\kappa \alpha$ l coronavirus/covid-19. The inclusion criteria were studies related to the topic, in English and Greek language, published in recent literature as shown in the flow diagram below. Expected and desirable results are the confirmation of effectiveness of the interdisciplinary teams in the timely diagnosis of in-hospital cardiac emergencies, resulting in a positive correlation of both concept though articles to be studied. In addition, the clarification of issues such as speed of action and the use of personal protective equipment through pandemic, always guided by the best for the health of patients and rescuers.

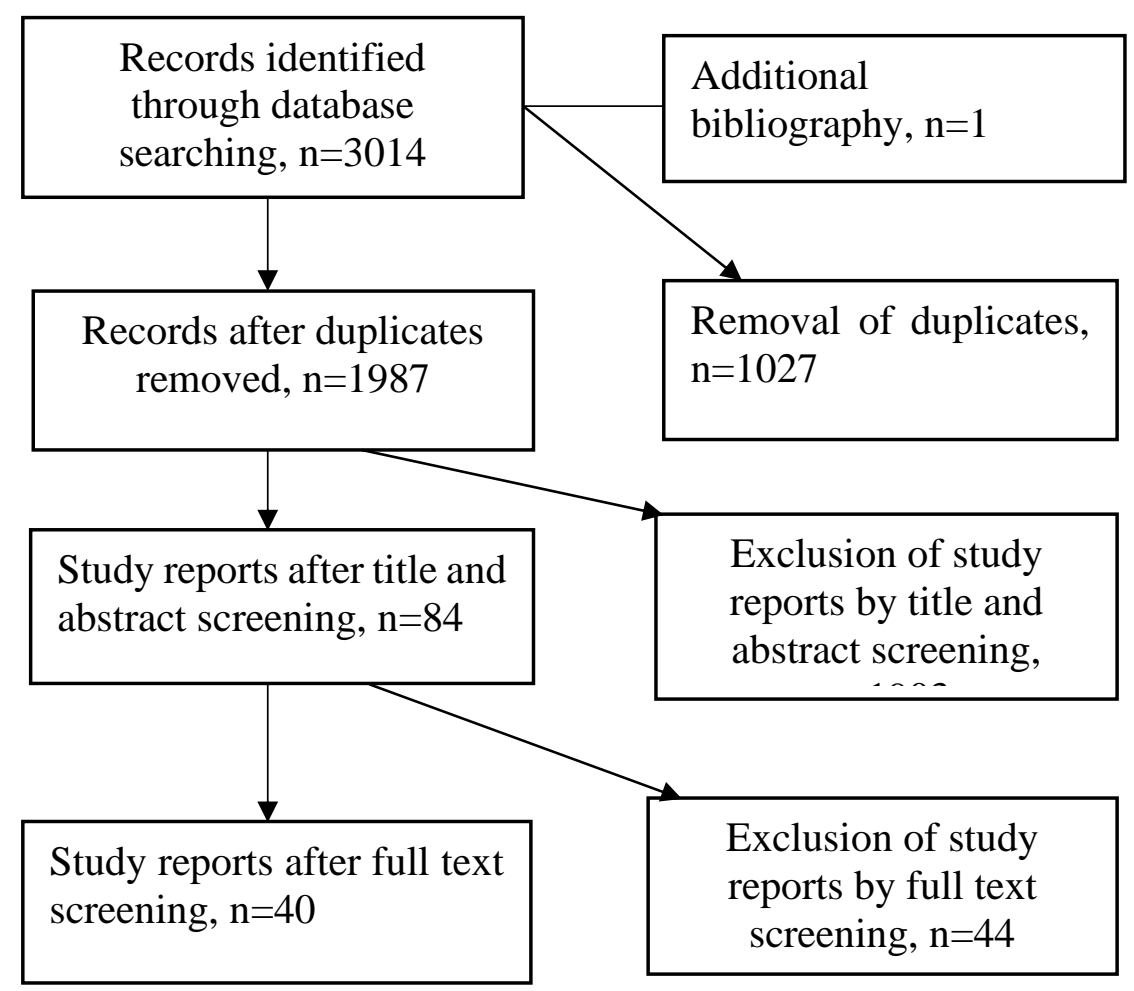

Figure 1: Flow diagram

\section{Results}

Every year, in-hospital CA occurs in more than 290.000 adults in the USA. Cohort data from 2019 in the USA show that the average age of the patients with in-hospital $\mathrm{CA}$ is 66 years, $58 \%$ are men and arrhythmia is more often (81\%) nondefibrillating.[18] The most common reason of cardiac arrest is cardiac (50\%-60\%) followed by respiratory (15\%-40\%). According to American Heart Association, 
from 2008 to 2017, in-hospital CAs were about 10 per 1000 admissions. Data from 2011 to 2013 show an 18\% survival rate, when cardiac arrest occurs, in the UK, while in Denmark and Sweden, survival of at least 30 days after CA is about 30\% in modern national records.

\subsection{Interdisciplinary Cooperation}

\subsubsection{Blue code}

According to a study conducted in 2018 in India, all patients who were called to the 'blue code' in a tertiary care hospital for 24 months, were analyzed and checked.[10] The mean duration of CPR in 422 patients with CA was found to be 15,6 minutes. Survival was significantly higher in patients with a CPR duration of $<15$ minutes. Age, heart rate and duration of CPR had a statistically significant effect on survival. A retrospective study in 2014 in Turkey analyzed the code blue calls issued by a hospital from 1 Jan. to 1 June 2012.[19] Totally, 89 blue code calls recorded in 5 months. The blue code was defined as any patient with unexpected cardiac or pulmonary arrest, who requires resuscitation and activation of a hospital alert. The mean age of the patients was 68 years, while $58(65,2 \%)$ were women and $31(34,8 \%)$ men. Activations were eventually diagnosed as CA ( 8 patients, $9 \%$ ), indicating that $81(91 \%)$ were blue-code calls errors. The activations of blue code were made by doctors in 68 patients (76\%), while the rest by nurses and other staff. The CPR percentage that occurred when the code blue team arrived was $100 \%$ in 8 patients with CA (in all), while the total response time was 5 minutes $\pm 10 \mathrm{sec}$. Finally, 6 of the 8 patients with CA were sent to the intensive care unit and 2 died.

\subsubsection{Interdisciplinary Teams}

A systematic review in 2018 in Brazil evaluating the effectiveness of RRTs in adult hospitals estimated studies published from 2000 to 2016.[20] A total of 12 studies evaluated the mortality rate and 9 of these studies yielded results showing that RRTs were associated with a significant reduction in mortality, with estimates ranging from $10-48 \%$. Of the other 3 (meta-analyzes), 2 reported no significant reduction in mortality, while the other (in 2015) showed a significant reduction in mortality. 11 studies examined the incidence of CA and 9, including 2 meta-analyzes, showed that RRTs were associated with significant reduction in the incidence of CA. The most recent meta-analysis (2015) included studies published up to 2013 and reported RRT efficacy rates with $13 \%$ mortality and 35\% CA. In Brazil, especially, RRTs were found to be associated with significant reductions in mortality (11\%) and CA $(52 \%)$.

In a 2008 study in Kansas City, Missouri there were 24.193 patient admissions evaluated before RRT intervention.[21] During the period of 20 months from the implementation of the intervention there were a total of 376 RRT activations. The most common reasons for activating the rapid response team were stroke $(27,4 \%)$, tachycardia $>130$ beats/min $(23,4 \%)$, tachypnea $>30 / \mathrm{min}$. (13,3\%) and systolic blood pressure lower than $90 \mathrm{mmHg}(11,7 \%)$. The most common RRT interventions 
taken were electrocardiogram (41.0\%), additional peripheral intravenous line access (40.0\%), arterial blood gas (32.2\%), and chest radiograph (31.1\%). After RRT activation, patients were transferred to a higher level of care in $45,5 \%$ of cases. The rates of blue code calls to hospital per 1000 admissions were $1,12 \%$ before RRT intervention and $0,75 \%$ after, decreased for all types of blue code events. However, survival rates of patients after CA were slightly different before and after RRT intervention with $77,9 \%$ before and $76,1 \%$ after.

A 5-year control study in Sweden in 2009 showed that the number of deaths (per 1,000 admissions) decreased after the introduction of RRT from 1.12 to 0.83 and a total reduction in hospital mortality of $10 \%$ was recorded.[22] In the same survey, individual semi-structured interviews were conducted with eleven Danish Advanced Life Support trainers. A framework was identified with fine categories in terms of non-technical skills: leadership, communication, monitoring individual performance, maintaining standards and guidelines, and managing tasks. Significant obstacles identified were the inexperience of the team leader, the workload and the non-observance of the hierarchy so that the team could focus on the CPR process.

Another study conducted in California in 2015 at two University hospitals from 2005 to 2011 showed that from 2006 to 2011, the incidence of in-hospital CA outside the ICU decreased from 2,7 to 1,1 per 1000 admissions.[23] Overall hospital mortality, from CA, also decreased during the study period from 2006 to 2011. Only $3 \%$ of activations did not result in intervention. The majority of patients $(99 \%)$ survived after RRT intervention. Overall, 56\% of RRT activations resulted in patients being transferred to a higher level of care [43\% transferred to ICU $\kappa \alpha 113 \%$ to intermediate care unit], while the remaining $44 \%$ of patients stayed on their original unit.

A retrospective data analysis was conducted in 2016 in France in the 4 hospitals of the regional care center of Montpellier.[24] Criteria for RRT activation were pulses below 40 or above 140/min., systolic blood pressure below $80 \mathrm{mmHg}$, cardiac or pulmonary arrest, respiration below 8 or above $30 / \mathrm{min}$, oxygen saturation below $90 \%$ and sudden deterioration or total loss of consciousness. The RRT activation was implemented using unique phone number. There were 68.086 patients in the pre-RRT period and 69.165 in the RRT period. The unexpected survival rate, per 1000 admissions, decreased significantly from 21,9 to 17,4 between the pre-RRT and post-RRT periods. With an average of approximately 18,000 hospital admissions/year and an average of 1 RRT activation/day, the application was associated with saving 1.5 lives/week. During 18 months, a total of 564 RRT interventions were performed (29.6 interventions/1000 admissions), with the average arrival time to be in 5 minutes.

A retrospective observational study was conducted at Hanyang University in Seoul, South Korea in 2020 at an 813-bed tertiary hospital.[25] The RRT system operated 24 hours a day, 7 days a week and included as staff 1 intensive care physician, 1 invasive cardiologist, 2 general practitioners and 1 ICU nurse. The total number of CA (per 1000 admissions) during the RRT implementation was 1.09, a decrease of 
$34 \%$ compared to the percentage before the RRT implementation. In the RRT period the total mortality was $15.51 / 1000$ admissions, significantly reduced compared to that before the RRT. Patients with delayed RRT activation had a longer hospital stay. In the USA and the UK RRTs can also be guided by nurses, while in Australia they are only guided by doctors. The following table summarizes the most important results from the implementation of the interdisciplinary teams: 
Table 1: Worldwide interdisciplinary teams, mortality and response calls.

\begin{tabular}{|c|c|c|}
\hline Study & Results & Percentages (\%) \\
\hline Brazil (2018) & $\begin{array}{l}\text { RRTs are associated with a significant } \\
\text { reduction in the incidence of CA and } \\
\text { mortality. }\end{array}$ & $\begin{array}{l}13 \% \text { reduction in mortality and } 35 \% \\
\text { in CA. In Brazil, especially, a } \\
\text { reduction in the incidence of } \\
\text { mortality }(11 \%) \text { and CA }(52 \%) .\end{array}$ \\
\hline $\begin{array}{l}\text { Kansas City, } \\
\text { Missouri (2008) }\end{array}$ & $\begin{array}{l}\text { Blue code calls decreased after RRT } \\
\text { application. Mortality after CA was } \\
\text { slightly different. }\end{array}$ & $\begin{array}{c}\text { Calls (per } 1000 \text { admissions) } \\
\text { decreased from } 1,12 \% \text { before the } \\
\text { RRT intervention and } 0,75 \% \text { after } \\
\text { the intervention. Mortality: from } \\
77,9 \% \text { to } 76,1 \% \text {. }\end{array}$ \\
\hline Sweden (2009) & $\begin{array}{l}\text { The number of deaths after the } \\
\text { introduction of RRT, as well as the } \\
\text { mortality in the hospital by } 10 \% \text {. }\end{array}$ & $\begin{array}{c}\text { Deaths (per } 1,000 \text { admissions) } \\
\text { decreased from } 1.12 \text { to } 0.83 \text {. }\end{array}$ \\
\hline California (2015) & $\begin{array}{l}\text { Overall hospital mortality has } \\
\text { dropped significantly. }\end{array}$ & $\begin{array}{l}\text { Overall, } 56 \% \text { of the RRT activations } \\
\text { resulted in the transfer of patients by } \\
43 \% \text { to the ICU, } 13 \% \text { to the } \\
\text { intermediate care unit while } 44 \% \\
\text { remained in the initial clinic. }\end{array}$ \\
\hline France (2016) & $\begin{array}{l}\text { Unexpected mortality rates decreased } \\
\text { significantly between the pre-RRT } \\
\text { and post-RRT periods. }\end{array}$ & $\begin{array}{l}\text { Reduction of mortality (per } 1000 \\
\text { admissions) from } 21.9 \text { to } 17.4 \text {. With } \\
\text { an average of approximately } 18,000 \\
\text { entries/year and 1 RRT } \\
\text { activation/day, the application was } \\
\text { associated with a lifespan of } 1.5 \\
\text { lives/week. In } 18 \text { months, } 564 \text { RRT } \\
\text { interventions were performed (29.6 } \\
\text { interventions/1000 admissions). }\end{array}$ \\
\hline $\begin{array}{l}\text { Hanyang } \\
\text { University in } \\
\text { Seoul, South } \\
\text { Korea (2020) }\end{array}$ & $\begin{array}{l}\text { The total number of CA during RRT } \\
\text { application decreased compared to } \\
\text { before RRT application. }\end{array}$ & $\begin{array}{l}\text { Cardiac arrests were } 1.09 \text { per } 1000 \\
\text { admissions ( } 34 \% \text { decrease). In the } \\
\text { RRT period the total mortality was } \\
15.51 / 1000 \text { admissions, significantly } \\
\text { reduced compared to that before the } \\
\text { RRT application. }\end{array}$ \\
\hline Brazil 2020 & $\begin{array}{l}\text { The number of cases treated increased } \\
\text { by } 2.6 \text { times compared to the period } \\
\text { before the pandemic, while the } \\
\text { severity of the disease and the number } \\
\text { of patients increased. }\end{array}$ & $\begin{array}{c}15,461 \text { RRT calls were made. The } \\
\text { number of cases/calls increased on } \\
\text { average from } 30.6 / \text { day to } 79.2 \text {, while } \\
\text { the critical cases on average from } 3.5 \\
\text { to } 22 \text {. }\end{array}$ \\
\hline $\begin{array}{l}\text { Brighton and } \\
\text { Sussex University } \\
\text { Hospitals, UK } \\
(\mathbf{2 0 2 0 )}\end{array}$ & $\begin{array}{l}\text { The number of calls for MET and } \\
\text { cardiac arrest increased significantly. }\end{array}$ & $\begin{array}{l}\text { The average Covid-19 MET calls } \\
\text { responding score increased from } 2.4 \\
\text { to } 3.7 \text { after the simulation. The mean } \\
\text { score of Covid-19 cardiac arrest calls } \\
\text { also increased from } 2.2 \text { to } 3.6 \text {. }\end{array}$ \\
\hline
\end{tabular}




\subsubsection{Communication}

A 2017 literature review in Mexico identified ten communication assessment tools in order to assess communication skills in teams working in emergencies.[26] Six tools $(60 \%)$ were designed to measure the communication performance of the whole team, while 4 tools (40\%) were designed to assess the communication skills of individual team members. Regardless of the type of analysis, the most frequently evaluated areas of behavior were leadership, teamwork, communication and situational awareness.

\subsubsection{Role of Nurses}

In 2019, a descriptive quality study was conducted in nine USA hospitals.[27] Nurses played three key roles in the in-hospital CA response: as the first to locate the patient in bed, as a member of resuscitation team and as a clinical or administrative leader. Differences were found between hospitals in terms of support for nurses. Higher-performing hospitals focused on the training and competence of nurses, provided organizational flexibility and responsiveness to nursing roles, and had authorized nurses to operate in a higher field of clinical practice. Higherperforming hospitals promoted nurses as RRT leaders and managers during resuscitation. Lower performing hospitals had more limited roles for nurses with less emphasis on systematically identifying improvement needs.

\subsubsection{Simulation Programs}

Based on the above, the need for staff training with CPR simulation seminars is demonstrated. A prospective, near-experimental design in the USA in 2016 evaluated the group training program for physicians, nurses, and physiotherapists.[28] Participants were treated for simulated CA. After the simulation, participants and trained observers evaluated the performance of teamwork using the TEAM (Team Emergency Assessment Measure) tool. This was followed by an update and 45 minutes of teamwork training. Participants took part in a second cardiac arrest simulation scenario. Participants and observers then evaluated the teamwork. 73 members participated, doctors (26\%), qualified nurses (33\%) $\kappa \alpha$ physiotherapists (41\%). Doctors had less experience in code blue teams. The average scores of participants (with the TEAM tool) for the first and second simulation were 3,2 and 3,7. The mean TEAM scores of observers for the first and second simulation were 3 and 3,7. The evaluations of the program by the participants were positive.

In a simulator-based randomized cross-over study, 30 anesthesiologists and anesthesia residents at VU University Medical Center in Amsterdam, the Netherlands in 2017 participated in two different CPR scenarios in random order.[29] External stressors were added to the first scenario (radio noise and family member interference), while the second scenario (stress-free) served as a control condition. Team leader non-technical skills and team technical skills were measured using the ANTS score that measures non-technical skills. All participants completed 
both CPR scenarios. Non-technical performance scores were significantly lower when there were external stressors compared to control scenarios (stress-free). In the group of participants who did the stress scenario first, the ANTS score increased significantly in the second scenario. Overall, it was observed that non-technical skills were associated with better overall performance and results.

\subsection{Covid-19}

Recent studies show that ICU admissions are required in 16-32\% of hospitalized patients with Covid-19, and that infection among healthcare providers was significantly high, especially when they were not prepared or did not wear adequate PPE (Personal Protective Equipment), with the USA CDC (Centers for Disease Control and prevention) report that healthcare providers accounted for up to $11 \%$ of confirmed Covid-19 cases in some states.[30,31] Dealing with in-hospital CA, which affects approximately 300,000 hospitalized patients in the USA each year in a non-pandemic year, is crucial.[32] In normal periods, more than 1 in 5 patients survive hospital discharge. During the pandemic, survival is much lower with significant delays in the delivery of potentially life-saving CPR, especially in the first minutes after cardiac arrest, as health professionals apply PPE. A total of 800 beds were modified as isolation wards for the admission of patients with severe Covid-19 pneumonia in January 2020 in Wuhan, China. Staff from other provinces were used to provide medical care in the general wards and ICUs. In some regions of the United States, patients with Covid-19 are already overloading many hospital wards, with hospitals running out of ICU beds, mechanical ventilators, and personal protective equipment (PPE) for health care providers.[33] ICUs have expanded their capacity around the world, but even with abundant resources this may not be possible or sufficient.

According to research in the USA in 2020, healthcare providers who apply CPR are at higher risk of contracting the disease.[34] Firstly, the administration of CPR involves the application of numerous aerosol procedures, including chest compressions and positive pressure ventilation. During those procedures, viral particles can remain suspended in the air with a half-life of $\approx 1$ hour. Secondly, resuscitation efforts require many professionals to be close enough, both to each other and to the patient. Third, the high stress of dealing with patients in need of resuscitation often leads to management and practice errors. According to the CDC, performed with PPE consisting of a gown, N95 masks, gloves, uniform, face shield and headgear, in isolation rooms given the high risk of transmitting the virus, even if efforts are delayed resuscitation.[35] Because full PPE may not normally be available outside of exclusive Covid-19 units, hospitals are considering adding it to their carts and supplying all members of the blue code team at the beginning of their changes.[33] .

Well-coordinated team dynamic is the key to improving efficiency and reducing the likelihood of infectious exposure during CPR.[33] Emergency Medical Services (EMS) teams are exposed to life-threatening events with patients in need of 
resuscitation.[36] French EMS teams are mobile resuscitation teams usually consisting of two doctors, a nurse and an ambulance driver.[37] Depending on the needs of the callers, either the EMS for primary care or the Covid-19 response team is notified to assess the risk factors for the virus.[36] The team follows an algorithm to detect and manage suspected Covid-19 cases. Based on the risk factors for the transmission of the virus and the clinical condition of the individuals, the Covid-19 response team determines the need for hospitalization, isolation at home, or laboratory testing.[36] In 4 case studies, three members of the EMS teams were infected with Covid-19, which highlights the need to comply with staff protection rules and review how EMS teams respond to ensure patient safety, staff of the EMS teams and the entire hospital.[37].

Another observational study reviewing medical records was conducted at a hospital in Fortaleza, Brazil in 2020.[38] A total of 15,461 RRT calls were made during the study period. Since the outbreak of the pandemic, the number of cases treated has risen by an average of 30.6 daily calls to 79.2 , while the extremely critical cases have increased from 3.5 to 22 . RRTs were made up entirely of healthcare professionals, responding to hospitalized patients, who were at risk of deterioration. Failure to detect patients whose situation is deteriorating may reduce the effectiveness of the groups. The number of members initially included 2 professionals with ICU experience, while during the pandemic, it expanded to 4 . The number of cases treated during the pandemic increased by 2.6 times compared to the previous period, while also increasing the severity of the disease and the number of patients. The Covid-19 pandemic also led to a higher occupancy rate of hospital units, as well as the conversion of some units into premises practically exclusively for patients with this disease. The MET emergency medical team responds to emergencies throughout the hospital.[30] It consists of physicians, the Critical Care Approach Team (CCOT) and intensivists. In a simulation program 56 people participated with the majority $(87.5 \%)$ stated that they had reviewed the updated guidelines on PPE, aerosolization procedures and adult life support (91\%, $84 \%$ and $91 \%$ respectively). All participants felt that through the simulation they improved their readiness to respond to a suspicious emergency call Covid-19. This was demonstrated by the fact that the average Likert score for responding to Covid19 MET calls increased after the simulation from 2.4 to 3.7, while the number of Covid-19 cardiac arrest calls increased from 2.2 to 3.6.

In Singapore, a simulation course conducted in a negative-pressure room within the ICU in 2020.[39] The participants were doctors and nurses from the ICU. Each simulation session had 8 to 10 participants: two doctors, three nurses and the rest were observers. The time it took to activate the blue code from the first responder wearing PPE ranged from 3 to 5 minutes. The time required from cardiac arrest to successful intubation ranged from 5 to 11 minutes. There was a reduction in the time taken for each of the key steps by conducting subsequent simulation sessions. The ideal roles for response teams included managing the airways by an experienced physician, providing medication by a second physician, assisting in the management of the airways by a first nurse, performing chest compressions by a 
second nurse alternating with the first and calling blue code. When RRT arrived the first nurse handed over the case to the team and acted as a runner nurse outside the isolation room, after properly removing the PPE, restricting staff movements between the isolation area and the rest.

At San Diego Health, University of California, USA, an Incident Management Center (ICC) was established in 2020 for 24-hour monitoring and adaptation to rapidly evolving conditions and recommendations.[40] Utilizing the capabilities of the Electronic Health Record (EHR) for quick updating and screening to reduce exposure and workload of health care centers, automated email notifications were sent to patients prior to their clinic appointments. The team members included 2 infectious disease specialists, 3 primary care physicians and 2 nurses. The development of an interdisciplinary team with the participation of experts in the prevention of Covid-19 infection is a crucial first step in responding and developing open and productive communication. 
Table 2: Interdisciplinary and RRT during COVID-19 pandemic

\begin{tabular}{|c|c|c|c|}
\hline Study & Teams & Organization/Members & Success \\
\hline $\begin{array}{c}\text { Brazil } \\
2020\end{array}$ & $\begin{array}{c}\text { Rapid Response } \\
\text { Teams (RRT) }\end{array}$ & $\begin{array}{l}\text { They consist of health } \\
\text { professionals. Mainly } 2 \\
\text { simultaneous on-duty } \\
\text { professionals experienced in } \\
\text { ICU, which, during the } \\
\text { pandemic period, was } \\
\text { expanded to } 4 \text {. }\end{array}$ & $\begin{array}{c}\text { The number of treated } \\
\text { cases increased (from } \\
30,6 \text { daily to } 79,2) \text {. The } \\
\text { number of cases treated } \\
\text { by the RRT increased } 2,6 \\
\text { times. }\end{array}$ \\
\hline $\begin{array}{c}\text { Brighton and } \\
\text { Sussex } \\
\text { University } \\
\text { Hospitals, UK } \\
2020\end{array}$ & $\begin{array}{c}\text { Medical Emergency } \\
\text { Team (MET) }\end{array}$ & $\begin{array}{l}\text { The multidisciplinary team } \\
\text { includes the medical registrar, } \\
\text { several junior doctors, the } \\
\text { CCOT and anesthetists/ } \\
\text { intensivists. The simulation } \\
\text { team consisted of } 1 \text { junior } \\
\text { doctor, } 2 \text { ward nurses, } 1 \text { ward } \\
\text { doctor and the medical } \\
\text { emergency / cardiac arrest team } \\
\text { (a 3-4 persons team). }\end{array}$ & $\begin{array}{l}\text { The simulations improved } \\
\text { their preparedness in } \\
\text { responding to emergency } \\
\text { call in patient with } \\
\text { suspected Covid-19. } \\
\text { Covid-19 MET calls } \\
\text { increased from 2,4 daily } \\
\text { to 3,7. Covid-19 cardiac } \\
\text { arrest calls increased from } \\
\text { 2,2 daily to 3,6. }\end{array}$ \\
\hline $\begin{array}{c}\text { France } \\
2020\end{array}$ & $\begin{array}{c}\text { Emergency Medical } \\
\text { Service (EMS) }\end{array}$ & $\begin{array}{c}\text { Mobile medicalized } \\
\text { resuscitation teams composed } \\
\text { of emergency physician, nurse } \\
\text { or anesthesiologic nurse, } \\
\text { ambulance driver, and a } \\
\text { resident. }\end{array}$ & $\begin{array}{l}\text { Four types of clinical } \\
\text { cases show the difficulties } \\
\text { faced by EMS teams in } \\
\text { the initial phase of the } \\
\text { Covid-19 epidemic in } \\
\text { France. }\end{array}$ \\
\hline $\begin{array}{l}\text { Singapore, } \\
\mathbf{2 0 2 0}\end{array}$ & $\begin{array}{c}\text { The simulation } \\
\text { conducted in a } \\
\text { negative-pressure } \\
\text { room within the } \\
\text { ICU. }\end{array}$ & $\begin{array}{l}\text { Medical and nursing staff from } \\
\text { ICUs and high dependency } \\
\text { units. }\end{array}$ & $\begin{array}{l}\text { There was a reduction in } \\
\text { total time taken for } \\
\text { responders to call code } \\
\text { blue team and for stuff to } \\
\text { conduct successful } \\
\text { intubation during cardiac } \\
\text { arrest. Flexibility of roles } \\
\text { was required during the } \\
\text { resuscitation. }\end{array}$ \\
\hline $\begin{array}{c}\text { University of } \\
\text { California, San } \\
\text { Diego Health } \\
2020\end{array}$ & $\begin{array}{c}\text { An Incident } \\
\text { Command Center } \\
\text { was established for } \\
\text { 24-hour monitoring } \\
\text { and adaptation to } \\
\text { rapidly evolving } \\
\text { conditions during the } \\
\text { pandemic. }\end{array}$ & $\begin{array}{l}\text { Consisting of } 2 \text { infectious } \\
\text { disease physicians, } 3 \text { primary } \\
\text { care physicians and } 2 \text { nurses. } \\
\text { Using a secured messaging } \\
\text { platform within the EHR to } \\
\text { enable rapid communication of } \\
\text { any new requirements or } \\
\text { updates. }\end{array}$ & $\begin{array}{l}\text { The development of a } \\
\text { multidisciplinary task } \\
\text { force is a critical first step } \\
\text { to address hospital- } \\
\text { specific concerns about } \\
\text { Covid-19 and develop } \\
\text { productive } \\
\text { communication. This } \\
\text { tool identifies } \\
\text { symptomatic patients } \\
\text { earlier and decrease the } \\
\text { physical burden on } \\
\text { healthcare systems. }\end{array}$ \\
\hline
\end{tabular}




\section{Discussion}

It is common knowledge that, nowadays acute cardiovascular diseases, and especially cardiac arrest, have increased significantly and this is mainly evident from the high mortality rates in Europe and the USA. The existence and establishment of interdisciplinary teams (such as RRT) and rapid response systems is considered crucial for the immediate effectiveness and management of emergency cardiovascular diseases with staff fully trained at CPR. According to research, RRTs worldwide are associated with significant reduction in the incidence of CA, mortality, unscheduled ICU admissions and the impact of CA, leading to better survival rates. Researches have also showed that survival rates from CA after the RRT implementation are significantly reduced. At the same time, in addition to reducing immediate mortality, hospital stays were reduced afterwards, a fact that directly affects patients' health and care costs, but also indirectly general mortality, for all diseases and pathological conditions for the distant future.

Furthermore, when it comes to team planning in the USA and the UK, RRTs can be led by nurses, while in Australia they are led by doctors only. Most commonly the main members of the team are 1 intensivist, 1 invasive cardiologist, 2 general practitioners and 1 nurse. According to research results, the successful exchange of information among team members has a positive effect on its performance, especially when communication tools are used. Indeed, studies from the USA, Mexico, and other countries have identified communication evaluation tools designed to measure the communication performance of the entire response team/ "blue code" as well as others created to assess the communication skills of individual team members. The most frequently assessed areas were leadership, teamwork, communication, situational awareness, foresight and generally the nontechnical skills of the internationally recognized 'ANTS' program which has systematically defined the mental, social and individual skills that complement technical skills and contribute to team effectiveness.

At the same time, in emergencies such as the recent covid-19 pandemic, global problems and dilemmas often arise. Apart from the clinically proven correlations of covid-19, both as a cause and as a result, with urgent cardiovascular diseases and events, the lack of specialized training and knowledge of the staff, the fatigue (which in this pandemic reached the limits of the medical staff), the use of complex protective clothing and equipment, but also the insecurity of the staff for immediate action can lead to delays in obtaining the potentially life-saving CPR, greatly reducing the survival rate.

Indeed, there is often a risk of CPR being delayed due to the application of personal protective equipment against the potential risk of transmission of Covid-19 to rescuers, other workers, patients and the wider community. Extreme perceptions of CPR not being performed in some Covid-19 patients have been adopted in some hospitals. However, such an approach may lead to non-potentially lifesaving interventions in patients with reversible causes of cardiopulmonary arrest, such as arrhythmias and other reversible disorders. Recommended exclusion criteria for 
CPR include confirmed Covid-19 case, lack of adequate PPE, significant comorbidities, advanced age, and other variables that reduce the likelihood of success. In these scenarios, the risk of aerosol formation and transmission of the virus outweighs the low chances of successful rescue. What needs to be incorporated into deciding whether or not to resuscitate is the lack of human and material resources often seen in pandemic outbreaks, which is often responsible for the poor outcome of Covid-19 patients and can lead to a lack of health personnel in the near future due to infection.

In such emergencies, well-coordinated interdisciplinary teams, such as the EMS teams in France, are a prerequisite for improving efficiency and reducing the likelihood of infection during CPR. Covid-19 is an emerging, rapidly evolving situation around the world that requires the creation of further new interdisciplinary teams of experts to deal with suspicious incidents and detect them timely. Protocols are required, with the option of first calling either EMS for primary care or Covid19 response teams to assess risk factors for infection. All this, of course, after the application of appropriate personal protective equipment, to ensure the safety of patients, staff of EMS teams and the entire hospital.

The training of medical staff with cardiac arrest simulation seminars in manikins and simulated patients showed, based on the results of assessment tools such as "TEAM" and others, a significant increase in RRT performance in the USA and other countries, which predisposes positive for their further use, organization and development in the future. The establishment of these teams in hospital, their immediate activation and the systematic and continuous training of their staff is a clear proposal, if not a one-way street, for the future in all hospitals, with the aim of reducing the incidence of cardiac arrest, hospitalization days and mainly of these mortality in hospitalized patients.

Finally, the multidimensional role of the nurse in 3 main areas for the treatment of $\mathrm{CA}$ and general cardiovascular events should be emphasized, which is irreplaceable and indisputable. Initially, nurse is usually the one who will be the first to notice the deterioration and danger of the patient's condition and will call the response team (RRT) immediately. In addition, the nurse, through his training technique, has the role of an equal member of the RRT and "blue code" teams, while finally he can be, through the non-technical skills he possesses, a clinical or administrative leader of the teams, as he has worked successfully and efficiently in many western countries.

\section{Conclusions}

Emergency cardiovascular diseases and events are increasing year by year worldwide, increasing the demand and cost of health services on the one hand, and overall morbidity and mortality on the other. The "interdisciplinary" cooperation of health professionals, mainly doctors and nurses, in the treatment and management of such emergency cardiovascular events in hospitalized patients has been institutionalized worldwide, either in the form of specific groups (RRT, MET, CCOT, etc.) or in the form of a blue code. Evaluation results have shown worldwide 
the contribution of these groups to reducing mortality and improving the overall health of patients and the health services provided. Communication tools have been developed for the organization and operation of these groups, with the predominantly internationally recognized SBAR and RSVP programs. The importance (beyond knowledge and technical training) of non-technical skills (such as teamwork, composure and leadership skills) of health professionals participating in such groups, through their evaluation and implementation programs such as the "ANTS" program, was also demonstrated, while at the same time, international CPR simulation programs with positive results have been developed and are constantly evolving. Further research has shown that promoting and supporting the role of nurses, even as RRT leaders, is associated with a positive outcome for patients. These groups are called through the coronavirus pandemic, to respond to new challenges, such as time management and the implementation of protection measures. The creation of new rapid response interdisciplinary teams, trained in pandemic conditions, will help reduce mortality, train staff and save resources for health systems in the midst of their global burden. 


\section{References}

[1] C.Lionis, B.Bibilaki, T.Adamakidou, E.Sakellari, The health team of Primary Health Care ( Definition-Concepts), chapter 2, (2015), 24-31.

[2] Jennifer Dunsford, Structured Communication: Improving Patient Safety With SBAR, Nurs Womens Health, 13(5), (2009), 384-90.

[3] Peter Featherstone, Tina Chalmers, Gary B Smith, RSVP: A System for Communication of Deterioration in Hospital Patients, Br J Nurs, 17(13), (2008), 860-4.

[4] R.Flin, R.Patey, R.Glavin, N.Maran, Anaesthetists' non-technical skills, $\mathrm{Br}$ J.Anaesth, 105(1), (2010), 38-44.

[5] Susan C. Dewit, Pathological and Surgery Nursing. Concepts and Practice, First edition, Broken Hill Publish, Nikosia Cyprus, 2009.

[6] A.Jagosz, D.Bursy, A.Sobon, P.Kiczmer, M.Copik, S.Bialka, J.Smereka, H. Misiolek , L.Szarpak, In-hospital sudden cardiac arrest protocol analysis, Kardiol Pol, 76(2), (2018), 376-380.

[7] European Resuscitation Council, Belgium, (2015), https://cprguidelines.eu/guidelines-2020 . [Access Day 23/11/2020].

[8] N. Stefanopoulos, F.Zykai, D.Chamilou, Investigation and mapping of AEDs in Greece, chapter 1, (2017),14-15.

http://repository.library.teimes.gr/xmlui/bitstream/handle/123456789/6019/p df? sequence=1\&isAllowed=y . [Access Day 23/11/2020].

[9] G. Kipourgos, E. Giannakopoulou, Recuscitation Team- Rapid Response Team and the role of nurses, chapter 2, (2018), 32-37.

http://repository.teiwest.gr/xmlui/handle/123456789/6953. [Access Day 23/11/2020].

[10] Srinivas Monangi, Rangraj Setlur, Ramprasad Ramanathan, Sidharth Bhasin, Mridul Dhar, Analysis of Functioning and Efficiency of a Code Blue System in a Tertiary Care Hospital, Saudi J Anaesth, 12(2), (2018), 245-249.

[11] Heather Wolfe et al, Interdisciplinary ICU Cardiac Arrest Debriefing Improves Survival Outcomes, Crit Care Med, 42(7), (2014), 1688-1695.

[12] Patrick G Lyons, Dana P Edelson, Matthew M.Churpek, Rapid Response Systems, Resuscitation, 128, (2018), 191-197.

[13] Mary Ann Peberdy et al, Recommended Guidelines for Monitoring, Reporting, and Conducting Research on Medical Emergency Team, Outreach, and Rapid Response Systems: An Utstein-Style Scientific Statement, Traffic, 116(21), (2007), 2481-2500.

[14] J. L Mitchell, Caroline W, Motschwiller, James M Horowitz, Laura E Evans, Vikramjit Mukherjee, Characterising variation in composition and activation criteria of rapid response and cardiac arrest teams: a survey of Medicare participating hospitals in five American states, BJM Open, 9(3), (2019).

[15] Bernard Fikkers, RRS Survey Results, 6th International Symposium Rapid Response Systems, Netherlands, (2010). 
http://rapidresponsesystems.org/Pittsburgh2010/2010pdfs/Pittsburgh_Survey _Results_Fikkers.pdf . [Access Day 23/11/2020].

[16] Andersen PO, Jensen MK, Lippert A, Østergaard D, Identifying non-technical skills and barriers for improvement of teamwork in cardiac arrest teams, Resuscitation, 81(6), (2010),695-702.

[17] Heng KW, Fong MK, Wee FC, Anantharaman V, The role of nurses in the resuscitation of in-hospital cardiac arrests, Singapore Med J, 52(8), (2011),611-5.

[18] Lars W.Andersen, Mathias J.Holmberg, Katherine M.Berg, Michael W. Donnino, Asger Granfeldt, In Hospital Cardiac Arrest: A Review, JAMA, 321(12), (2019), 1200-1210.

[19] Serkan E.Eroglu, Ozge Onur, Oğuz Urgan, Arzu Denizbasi, and Haldun Akoglu. Blue Code: Is it a real emergency?, World J Emerg Med, 5(1), (2014), 20-23.

[20] Hermano Alexandre Lima Rocha, Antônia Célia de Castro Alcântara, Sabrina Gabriele Maia Oliveira Rocha, Cristiana Maria Toscano, Effectiveness of rapid response teams in reducing intrahospital cardiac arrests and deaths a systematic review and meta-analysis, Rev Bras Ter Intensiva, 30(3), (2018), 366-375.

[21] Paul Chan et al, Hospital-wide Code Rates and Mortality Before and After Implementation of a Rapid Response Team, JAMA, 300(21), (2008), 2506-13.

[22] David Konrad et al, Reducing in-hospital cardiac arrests and hospital mortality by introducing a medical emergency team, Intensive Care Med, 36(1), (2010), $100-6$.

[23] Daniel P Davis et al, A novel configuration of a traditional rapid response team decreases non-intensive care unit arrests and overall hospital mortality, J Hosp Med, 10(6), (2015), 352-7.

[24] Boris Jung et al, Rapid Response team and hospital mortality in hospitalized patients, Intensive Care Med, 42(4), (2016), 494-504.

[25] Byuk Sung Ko et al, The effectiveness of a focused rapid response team on reducing the incidence of cardiac arrest in the general ward, Medicine (Baltimore), 99(10), (2020), 19032.

[26] Shady A Rehim, Stephanie DeMoor, Richard Olmsted, Daniel L Dent, Jessica Parker-Raley, Tools for Assessment of Communication Skills of Hospital Action Teams: A Systematic Review, J Surg Educ, 74(2), (2017), 341-351.

[27] Timothy Guetterman et al, Nursing roles for in-hospital cardiac arrest response: higher versus lower performing hospitals, BMJ quality \& safety, 28(11), (2019).

[28] Tara L Mahramus, Daleen A Penoyer, Eugene ME Waterval, Mary L Sole, Eileen M Bowe, Two Hours of Teamwork Training Improves Teamwork in Simulated Cardiopulmonary Arrest Events, Clin Nurse Spec, 30(5), (2016), 284-91. 
[29] Ralf Krage et al, Relationship Between Non-Technical Skills and Technical Performance During Cardiopulmonary Resuscitation: Does Stress Have an influence?, Emerg Med J, 34(11), (2017), 728-733.

[30] Foong Theng W et al, Rapid training of healthcare staff for protected cardiopulmonary resuscitation in the COVID-19 pandemic, British journal of anaesthesia, 125(2), (2020), 257-9.

[31] Cheruku Sreekanth et al, Cardiopulmonary Resuscitation in Intensive Care Unit Patients with Coronavirus Disease 2019, Journal of cardiothoracic and vascular anesthesia, 34(10), (2020), 2595-2603.

[32] Paul S. Chan, Robert A. Berg, Vinay M. Nadkarni, Code Blue During the COVID-19 Pandemic, Circulation: Cardiovascular Quality and Outcomes, 13(5), (2020).

[33] Fei Shao et al, In-hospital cardiac arrest outcomes among patients with COVID-19 pneumonia in Wuhan, China, Resuscitation, 151, (2020), 18-23.

[34] Dana P. Edelson et al, Interim Guidance for Basic and Advanced Life Support in Adults, Children and Neonates with Suspected or Confirmed COVID-19, Circulation, 141(25), (2020), 933-43.

[35] Ersilia M DeFilippis, Lauren S Ranard, David D Berg, Cardiopulmonary Resuscitation During the COVID-19 Pandemic: A View from Trainees on the Front Line, Circulation, 141(23), (2020), 1833-1835.

[36] Daniel Aiham Ghazali et al, Feedback to Prepare EMS Teams to Manage Infected Patients with COVID-19: A Case Series, Prehosp Disaster Med, 35(4), (2020), 451-453.

[37] Stefano Spina et al, The response of Milan's Emergency Medical System to the COVID-19 outbreak in Italy, Lancet, 395(10227), (2020), 49-50.

[38] Hermano Alexandre Lima Rocha et al, Dealing with the impact of the COVID19 pandemic on a Rapid Response Team operation in Brazil: Quality in practice, International Journal for Quality in Health Care, Internet paper, (2020), 1-4.

[39] Rhys D Wenlock, Amy Arnold, Hiten Patel, David Kirtchuk, Low-fidelity simulation of medical emergency and cardiac arrest responses in a suspected COVID-19 patient - an interim report, Clin Med (Lond), 20(4), (2020), 66-71.

[40] J. Jeffery Reeves et al, Rapid response to COVID-19: health informatics support for outbreak management in an academic health system, J. Am Med Inform Assoc, 27(6), (2020), 853-859. 